Y. Abdallah ${ }^{1 *}$, R. Ben Cheikh ${ }^{1}$, M. C. Paiva ${ }^{2}$

${ }^{1}$ Laboratoire de Matériaux, d'Optimisation et d'Energie pour la Durabilité, Ecole Nationale d'Ingénieurs de Tunis, Université Tunis El Manar, Tunis, Tunisie

${ }^{2}$ Department of Polymer Engineering, Institute for Polymers and Composites, Campus de Azurem, University of Minho, Guimarães, Portugal

\title{
Could Alfa Fibers Substitute Glass Fibers in Composite Materials?
}

In the present work polyester resin composites with Alfa fibers in the form of pulp were prepared and their properties were compared with those of polyester resin reinforced with glass fibers, the latter composites being widely used for structural applications. The composites were prepared using two manufacturing processes, namely hand lay-up and vacuum molding, to assess the influence of the process on the composites properties. Firstly, the tensile properties for the two composites were evaluated. The composites thermal properties were studied by differential scanning calorimetry and thermogravimetric analysis. Finally, the morphology of a glass fiber composite (GFC) and Alfa pulp composite (APC) was analyzed by scanning electron microscopy, to characterize the composites surface and cross-sections.

\section{Introduction}

The extraordinary development of composite materials that invaded our everyday life in areas as varied as building and construction, transportation, automotive applications etc., is explained by the multiple qualities of these materials, among which hydrophobicity, low density, deformability and mechanical strength are most relevant.

However, the impact of these materials on the environment, the awareness of our industrialized societies on waste management issues, and the growing concerns about the cost of synthetic composites, have led to the search for their replacement with more advantageous materials, namely the integration of biodegradable reinforcement substitutes from renewable materials such as natural fibers.

The development of composite materials with natural reinforcements that can compete with the most widely used composites in several industrial sectors, namely glass fiber reinforced composites is a very promising and constantly growing field of research. Indeed, non - structural composites made of

\footnotetext{
* Mail address: Yousra Abdallah Laboratoire de Matériaux, d'Optimisation et d'Energie pour la Durabilité, Ecole Nationale d'Ingénieurs de Tunis, Université Tunis El Manar, BP 37, Le Belvédère 1002, Tunis, Tunisie

E-mail: yousra.abdallah0903@gmail.com
}

natural fibers have already been marketed especially in the automotive sector, for the manufacture of the internal door panels (Holbery and Houston, 2006; Mater, 2008), because of their low density, their reduced cost of raw material, their ease of use and maintenance, and their biodegradability. Moreover, in building applications, wood plastic composites are increasingly accepted. The potential of natural fiber composites (NFC) for new applications is huge.

The selection of natural fibers as reinforcement in composite materials can naturally turn into wealth in countries where it is plentiful (Satyanarayana et al., 1986; Satyanarayana, 1990). In general, natural fibers can be classified according to their plant, animal or mineral origin. Fibers extracted from plants may be categorized according to the part of the plant from which they originate. For example, they may be extracted from leaves (banana, sisal, etc.), seeds (cotton), stems (hemp, jute, etc.), fruit (coir), root (vetiver) and also from wood. In this work, Alfa fiber, also known as Esparto Grass, extracted from the plant Stippa tenacissima, was selected. This plant is cultivated abundantly in the dry regions of North Africa, (Ammar et al., 2006; Ben Brahim and Ben Cheikh, 2007; Gracia-Fayos and Gasque, 2006) particularly in Tunisia where it covers 743 thousand hec-

Abbreviations
Materials
AP Alfa Pulp
APC: Alfa Pulp Composite
GF: Glass Fiber
GFC: Glass Fiber Composite
PE: Unsaturated Polyester Resin
VM: Vacuum Molding
Techniques
DSC: Differential Scanning Calorimetric
DTG: Derivative Thermogravimetric Curves
SEM: Scanning Electron Microscopy
TG: Thermogravimetric Curves
TGA: Thermogravimetric Analysis


tares with an annual production estimated at 42 thousand tons (Khiari, 2010) Alfa is mostly used in the production of paper (Paiva et al., 2007) but in recent years several studies have shown its potential as reinforcement for composites (Ben Brahim et al., 2001; Compos et al., 2003).

Although natural fiber composites have advantages, their hydrophilic nature (Karmaker et al., 1994) and low mechanical performance compared to synthetic reinforced composites remain an obstacle to their widespread use as a substitute for glass fiber. However, its reinforcing ability is quite relevant in particular when good adhesion between fiber and matrix is observed, or when it can be induced by performing physical (Baley et al., 2006; Belgacem et al., 1994; Felix, 1994; Gassan and Gutowski, 2006; Liu et al., 1994; Thomsen et al., 2006; Van de weyenbery et al., 2006) or chemical treatments (Joffe et al., 2003; Kostic et al., 2008; Rana et al., 1997; Troedec et al., 2008; Zafeiropoulos et al., 2007). In the latter case the major disadvantage is associated to the additional cost of fiber treatment.

The present work aims at providing a comparative study of the mechanical, thermal and morphological characteristics of two composites, namely a synthetic reinforced composite with glass fibers and a natural fiber reinforced composite. The natural fibers are Alfa pulp, which is already produced and marketed in Tunisia (SNCPA, 2018). To assure performance improvement in natural fiber composites, the fabrication process of the composite was modified in order to overcome the matrix-fiber adhesion issues without going through fiber treatment, and thus to guarantee the low cost of the materials. This may prove to be an interesting alternative for the industry in applications that do not require high mechanical properties but are rather focused on the environmental (eco-friendly) and technical (lightness, sound absorption ...) advantages associated to such fibers.

\section{Material and Methods}

\subsection{Raw Materials}

The natural reinforcement used in this work is Alfa pulp which is produced and marketed by SNCPA, Société Nationale de Cellulose et de Papier Alfa ( $\square$ Town $\square$, Tunisia). The alfa pulp mat is formed by randomly ordered fibers with an aerial weight of $524 \mathrm{~g} / \mathrm{m}^{2}$. The matrix material used for the preparation of both Alfa reinforced composite and glass fiber reinforced composite is the unsaturated polyester resin EASYLAM LSE produced by Polynt, $\square \square$ town, country $\square \square$. Its general properties are given in Table 1. The glass fiber used in this work is type E produced by Jushi France SAS, — town, country $\square$, which is a randomly ordered mat with an aerial weight of $350 \mathrm{~g} / \mathrm{m}^{2}$.

\subsection{Composites Processing Manufacturel Experimental Procedure}

In order to compare Alfa fiber reinforced composites to glass fiber reinforced composites, we prepared test samples with natural fibers in the same way as glass fibers. The process used for molding the reinforced unsaturated polyester resin is the con-

\begin{tabular}{|c|c|}
\hline Properties & Value \\
\hline Reactivity & \\
Method & $\mathrm{R} 151$ \\
Test temperature & $23^{\circ} \mathrm{C}$ \\
Catalyst system & $1.5 \%$ PMEC 50 \\
Gel time & $20-25 \mathrm{~min}$ \\
Peak time & $30-42 \mathrm{~min}$ \\
Temperature at peak & $70-90^{\circ} \mathrm{C}$ \\
& \\
Mechanical properties & \\
(cured resin non-reinforced) & \\
Post cure (16 h at 40 ${ }^{\circ} \mathrm{C}$ and $2 \mathrm{~h}$ at $\left.90^{\circ} \mathrm{C}\right)$ & \\
Tensile ISO 527 (1999) & \\
- Young modulus (MPa) & 3550 \\
- Tensile stress at break (MPa) & 45 \\
- Tensile strain at break (\%) & 1.55 \\
Flexural ISO 178 (2003) & \\
- Young modulus (MPa) & 3500 \\
- Flexural stress at break (MPa) & 90 \\
\hline
\end{tabular}

Table 1. Polyester unsaturated resin properties

tact molding which is a fully manual process. Reinforcing layers of fiber in the form of mats and catalyzed liquid resin are deposited successively on the mold surface, each layer is manually deposited and then impregnated with resin by means of a roller and a brush until the desired final thickness is achieved. The removal of air inclusions is an essential step. Once the final layers of fiber are applied to the mold, the resin undergoes gelification and cure. For this molding technique, the only pressure exerted is that made by the operator.

For the second type of manufacturing, we used the vacuum molding process, the procedure is the same as the contact molding except that the lamination is subsequently subject to vacuum using a waterproof tarpaulin, joints, pipes and a vacuum pump after the installation of a tear-off fabric and then a drainage felt placed directly on the laminate surface. A higher quality composite is then obtained compared to the contact molding composite, the fiber content is higher because the excess resin is extracted by the vacuum generated evenly across the composite during air elimination.

\subsection{Mechanical Properties}

Tensile tests were performed using an universal testing machine (model 1125, Instron, $\square$ town country $\square \square$ ). The resulting load was measured using a $25 \mathrm{kN}$ load cell. Tensile tests were carried out in accordance with ISO 527-4 (1997) at room temperature. The cross-head speed used for the type 1B tensile specimens was $2 \mathrm{~mm} / \mathrm{min}$ and the load was applied until the specimen failed. The specimens were tested without end tabs, showing valid failure modes as illustrated in Fig. 1. The mechanical analyses were repeated five times per sample, and the average and standard deviation were used as representative values. 


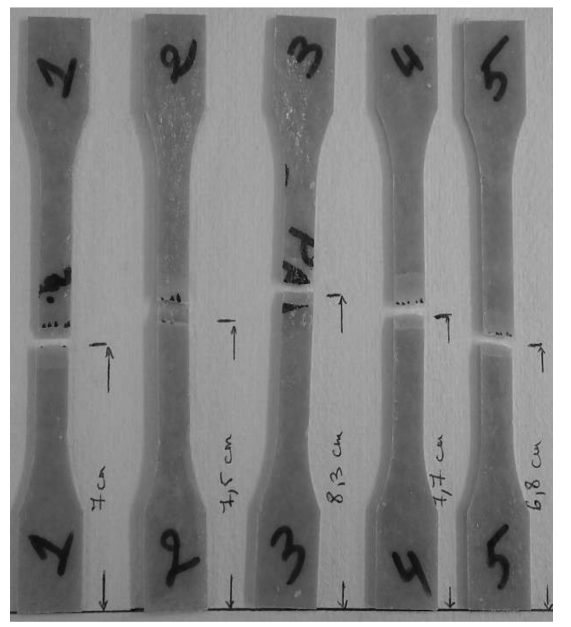

Fig. 1. Typical tensile failure mode for composites

\subsection{Morphological Testing}

In order to carry out a morphological characterization for the different samples, a top view of the reinforcing fibers (GF, AP) and an observation of the cross section of the composites (GFC, AFC) was performed using scanning electron microscopy (SEM).

The morphology of the different samples was characterized

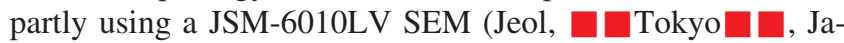
pan), operating at an accelerating voltage of $15 \mathrm{kV}$, and partly using a NanoSEM Fei Nova 200 microscope ( $\square$ company, town, country $\square$ ). For the observation of the composite morphology across the thickness, the composite specimens were dipped in liquid nitrogen and cryo-fractured. Before each analysis, the samples were sputtered with a gold layer, using a

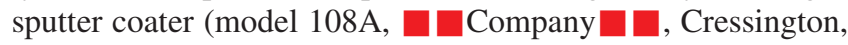
UK).

\subsection{Thermal Analysis}

\subsubsection{Thermogravimetric Analysis}

Thermogravimetric analysis (TGA) was performed on TA Q500 equipment (TA Instruments, $\square$ town $\square \square$, USA). Approximately $4 \mathrm{mg}$ of each reinforcement fibers and about $10 \mathrm{mg}$ of each composites were cut. The TGA curves were obtained by measuring the mass of a sample and heating it at a constant rate of $10^{\circ} \mathrm{C} / \mathrm{min}$ from 30 to $1000{ }^{\circ} \mathrm{C}$ under a constant flow of $60 \mathrm{ml} / \mathrm{min}$ of nitrogen.

\subsubsection{Differential Scanning Calorimetry}

Differential scanning calorimetry (DSC) measurements were performed on Diamond equipment (Perkin Elmer, $\square$ town, country u) under flowing argon atmosphere between $0{ }^{\circ} \mathrm{C}$ and $200^{\circ} \mathrm{C}$ at a heating rate of $10^{\circ} \mathrm{C} / \mathrm{min}$.

\section{Results and Discussion}

\subsection{Morphological Characterization}

Firstly, SEM observation for the two mats (mats of Alfa pulp and mats of Glass fibers) was carried out in order to observe the characteristics of the two types of reinforcement and how they may influence the properties of the composites (APC and GFC). In a global view, the two mats are formed by randomly arranged fibers which give them an almost isotropic character (Fig. 2A and B). However, the glass fibers mat is formed by long straight fibers which are identical and have a similar diameter while the mat of Alfa pulp consists of disordered fibers whose apparent diameter varies between 5 and 14 microns (Fig. 2E).

It is also noticed that the mat of glass fibers is formed by well-aligned straight fibers whereas that of the Alfa fibers contains aligned fibers but also fibers with small and large deformations (Fig. 2C and D). These deformations are due to the manufacturing process of the Alfa pulp during which the fibers undergo severe compressive stresses which cause a sudden change in the fiber axis alignment (Ellouze et al., 2017; Seth, 2006) and can even generate nodes which may strongly affect the mechanical properties of the fiber and subsequently of the composite. This can be explained by the fact that the Alfa fiber consists of micro fibrils of cellulose bonded together by lignin and hemicellulose (Fig. 2F). In fact the Alfa plant undergoes chemical extraction during which a large part of lignin and hemicellulose will be eliminated to retain the maximum cellulosic part of the stem. The non-eliminated parts constitute the matrix that binds the cellulose micro fibrils together that constitute the Alfa fibers. Thus, the Alfa fiber in itself is a composite whose reinforcement is micro fibrils of cellulose and the matrix is lignin and hemicelluloses (Jacob John and Thomas, 2008).

\subsection{Mechanical Properties}

\subsubsection{Tensile Test Result for the Composites Produced by Contact Molding Process}

The stress-strain curves for Alfa pulp reinforced composite and glass fiber reinforced composite can be seen in Fig. 3A. The Young's modulus, strength and strain for each composite are displayed in Fig. 3B, C, D in which the tensile properties of the unsaturated polyester resin, obtained from the manufacturers datasheet (Table 1), was added for comparison. The reported interval in the columns represents the standard deviation of the mean value obtained for the 5 specimens tested.

The composites' Young's modulus was compared to that of the unsaturated resin. The two composites showed a significant increase in stiffness. Indeed, the modulus of the GFC increases by $88 \%$ and the one of the APC increases by $68 \%$ compared to the base resin (Fig. 3B). To compare the two composites in term of tensile properties, the GFC showed greater tensile modulus ( $>12 \%$ higher). However, the strength of the GFC increases by $74 \%$ while the strength of the APC decreases by $42 \%$ compared to the resin (Fig. 3C). Also, the tensile strain at break of the GFC was nearly $62 \%$ higher than the strain at 


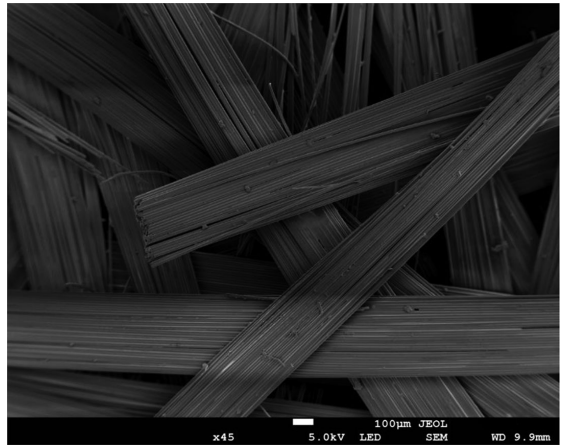

A)

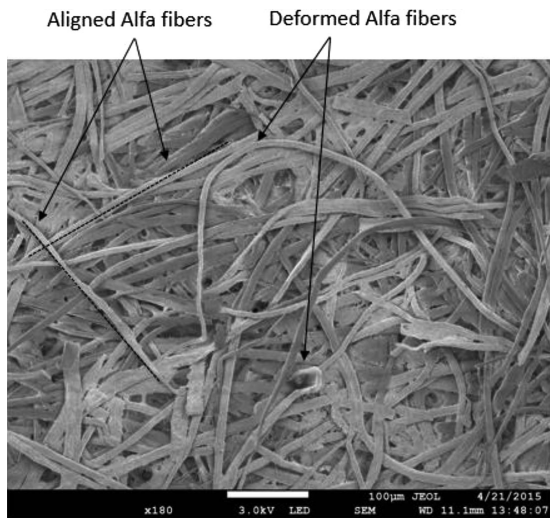

D)

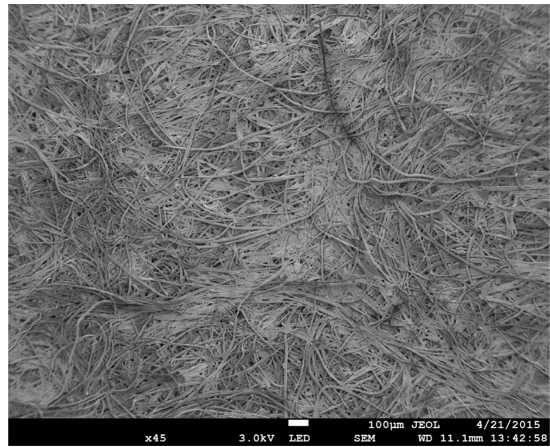

B)

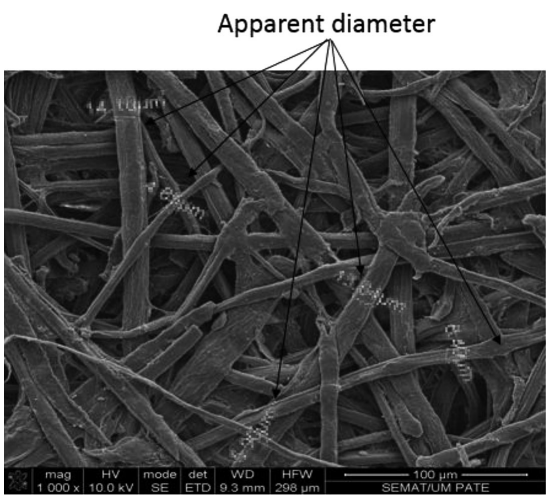

E)

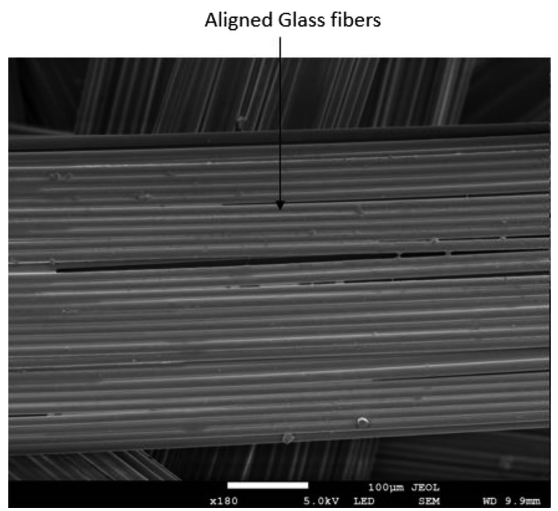

C)

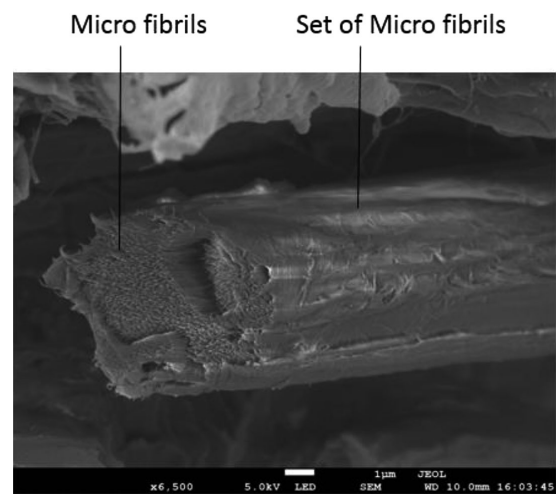

F)

Fig. 2. SEM of the top view of compressed mats: A) and C) glass fibers, B), D) and E) Alfa pulp, and F) a detail of the cross section of an Alfa fiber

break of the resin while the tensile strain at break of the APC was nearly $55 \%$ less than the tensile strain of the resin (Fig. 3D). Although the stiffness of the natural reinforced composite was considerably increased, the strength and strain have shown a substantial decrease compared to the base resin. This suggests that the matrix fiber adhesion is poor (Kaddami et al., 2006; Gloria et al., 2017) or that the composite may contain voids that cause this property degradation. It is also possible that the mat of Alfa is not homogeneous, containing regions of fiber agglomeration and regions of low fiber density that weaken the reinforced composite.

SEM observation of the composites cross sections were informative about the reasons underlying the decrease in the tensile strength and strain of the APC compared to the base resin. The micrographs illustrate the composite impregnation quality as well as the matrix-fiber adhesion.

The SEM observations of the APC (Fig. 4A) shows several regions that were not wet by the matrix, originating voids within the composite, unlike the SEM of GFC (Fig. 4B) which shows an effective wetting of fibers by the resin. The presence of large voids will dramatically decrease the tensile strength and strain of the composite. Thus the GFC presented better properties compared to APC.

In conclusion, in order to design a composite material with adequate mechanical properties, it is critical to have a perfect impregnation of the fibers by the matrix, a strong interfacial adhesion and a good dispersion of fibers. Therefore, in order to improve the adhesion between the Alfa pulp and the resin, vacuum molding was selected for the preparation of new composites. The produced composite is expected to present better fiber-matrix contact and to be free of voids, thus improving its properties compared to contact molding. The final composite fiber content is higher since the excess resin is eliminated by the vacuum created during the evacuation.

\subsubsection{Tensile Test Result for the Composites Produced by Vacuum Molding Process}

According to the stress-strain curve of composites shown in Fig. 5A, it's clear that a significant improvement of the mechanical properties was accomplished on the composite made with vacuum molding process. The increase in Young's modulus, strength and strain for each composite are clearly displayed in Fig. 5B, C, D. Just as the first tests, the properties of the unsaturated polyester resin have been added to the three graphs for comparison. In fact, we notice that when the process was modified, the tensile stiffness of the APC.VM improved greatly. It increased by about $20 \%$ compared to the stiffness of the APC made without vacuum process and it even exceeded the GFC's stiffness by about $7 \%$. On the other hand, the strength of the APC.VM increases by $38 \%$ compared to the strength of the PE 


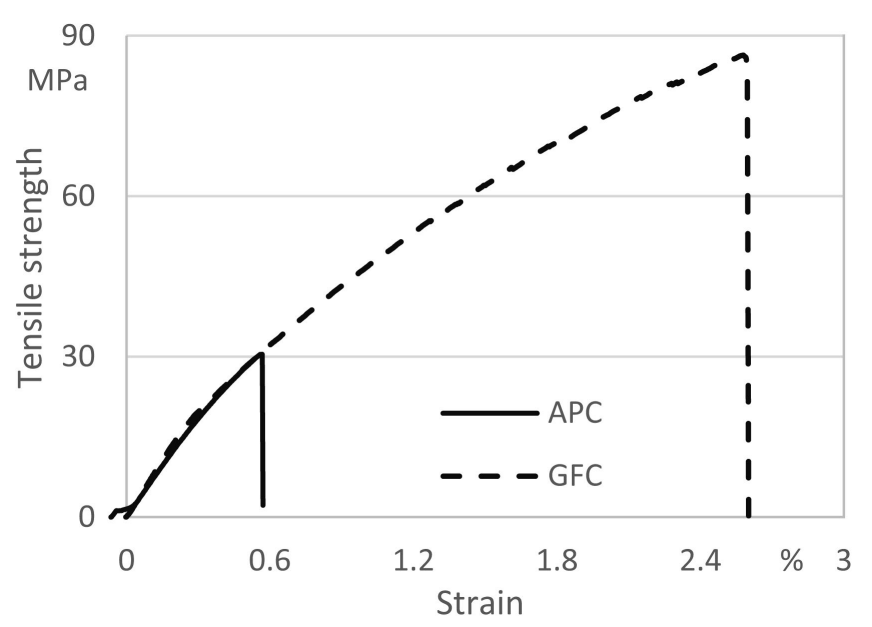

A)

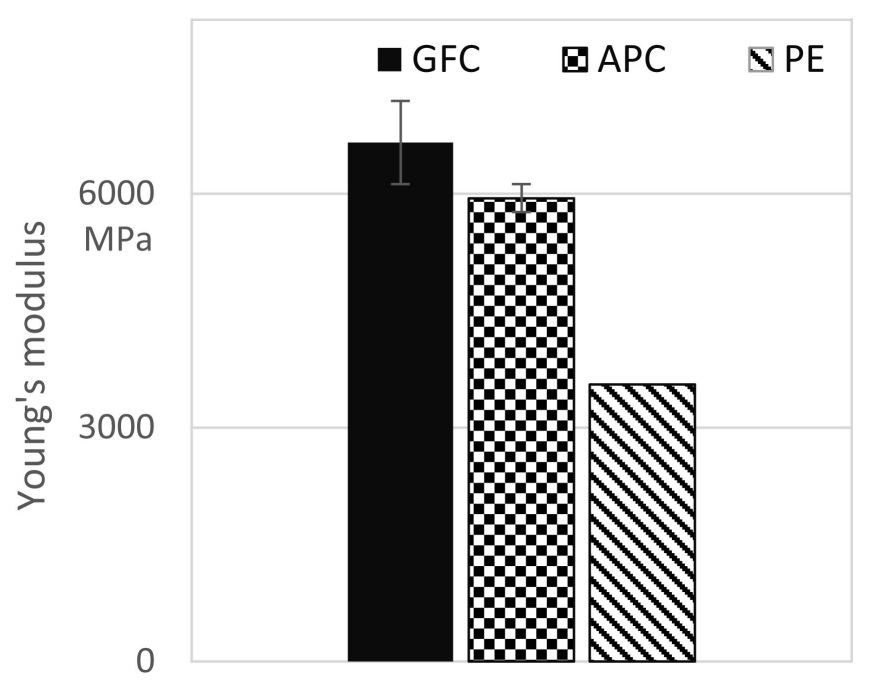

B)

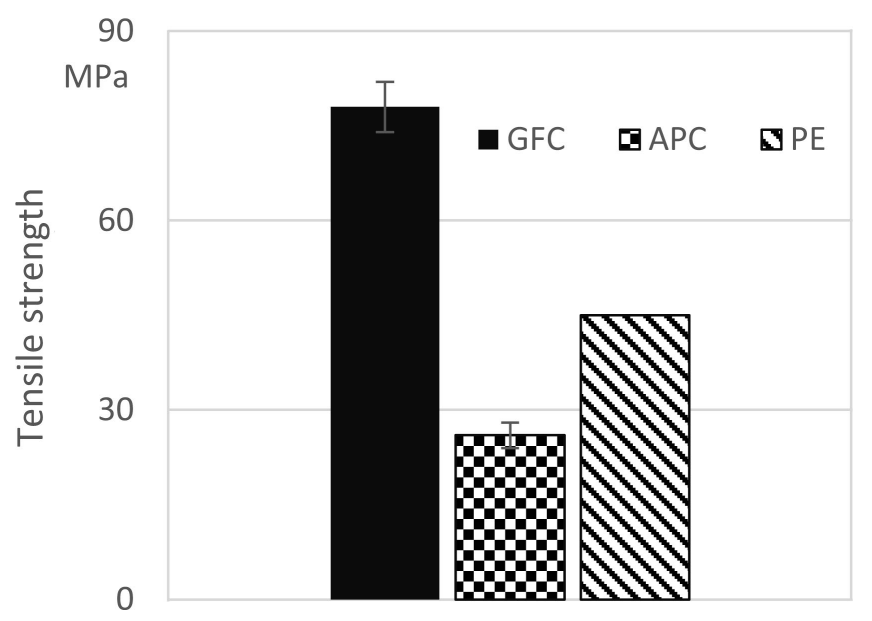

C)

Fig. 3. Tensile properties of GFC, APC and PE: A) typical stressstrain curves obtained for APC and GFC, B) Young's modulus of $G F C, A P C$ and $P E, C$ ) tensile strength of $G F C, A P C$ and $P E, D)$ tensile strain at break of GFC, APC and PE (with contact molding it was $42 \%$ less than the PE). Also the strain at break of the APC.VM increases by $3 \%$ compared to the strain of the PE (with contact molding it was $42 \%$ less than the PE). As global result, the GFC still has higher deformation and tensile strength than the APC made with vacuum molding but the difference is a moderate one. We can even conclude that the two composites have comparable properties.

The major difference observed on the tensile properties for APC produced with contact molding compared to APC produced with vacuum molding relates to the vacuum process that eliminates the voids present between the matrix and the fiber. It is also apparent that the adhesion between AP and resin was significantly improved, and thus the properties of APC became close to those for GFC. SEM observations of the two composites illustrate these effects, as depicted in Fig. 6. SEM of a fractured surface of GFC shows no gaps between glass fiber and polyester indicating a good interfacial bonding (Fig. 6B). The SEM micrograph of APC (Fig. 6A) shows parts whose fibers completely impregnated by the polyester confirming a good adhesion and compatibility between the two materials. A few holes can be observed on the fracture surface indicating pulled out fibers (Chuai et al., 2001).

These results are promising especially considering that the natural Alfa fiber is considerably lighter than the glass fiber, having a density of 1.4 while the density of glass fiber is near 2.5 (Mohanty et al., 2000; Wambua et al., 2003). This means that the specific strength and modulus (strength and modulus divided by the material density) of the natural fiber composite will be much larger compared to glass fiber composite. It should be stressed that the mat of Alfa pulp contained randomly distributed fibers of different diameters producing a heterogeneous composite, which affects the mechanical properties of the composite.

\subsection{Thermal Properties}

\subsubsection{Thermogravimetric Analysis}

The thermal degradation of Alfa pulp was analyzed and compared to that of the unsaturated polyester and the APC. The thermograms (TG) and their derivative (DTG) for materials (PE, AP, APC, GF, and GFC) are shown in Fig. 7 and 8 respectively.

For the Alfa pulp specimen, the first weight loss was before $100^{\circ} \mathrm{C}$. This is the drying phase justified by the hydrophilic character of the Alfa, and until $200^{\circ} \mathrm{C}$ the sample of AP did not lose weight, meaning that Alfa fibers are stable until around this temperature. The second phase corresponds to the thermal degradation of the AP .This is due to the degradation of cellulose in the form of dehydration, decarboxylation, depolymerisation and decomposition of glycosyl units, forming a charred residue of $12,6 \%$ that remains stable above $700{ }^{\circ} \mathrm{C}$ (Albano, 1999; Ouajai and Shanks, 2005).The TG curve of the polyester showed a lower amount of residual char of about $7 \%$, obtained at approximately $500^{\circ} \mathrm{C}$. The APC showed a weight loss of $88 \%$ above $700^{\circ} \mathrm{C}$, leaving a residue similar to the residue obtained for the Alfa fiber. As expected the GF are thermally stable across the whole temperature range studied and the large residual weight observed of GFC reflects mainly its GF con- 


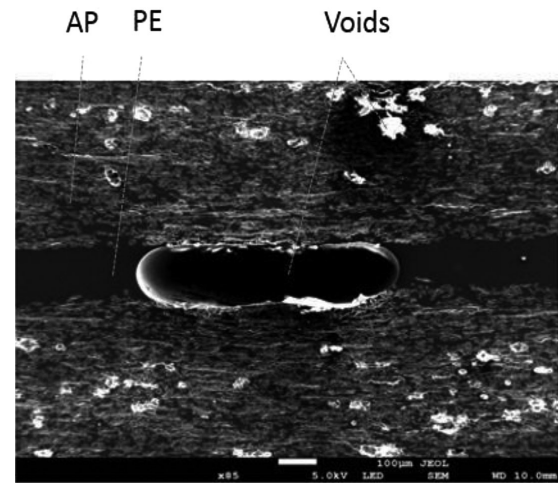

A)

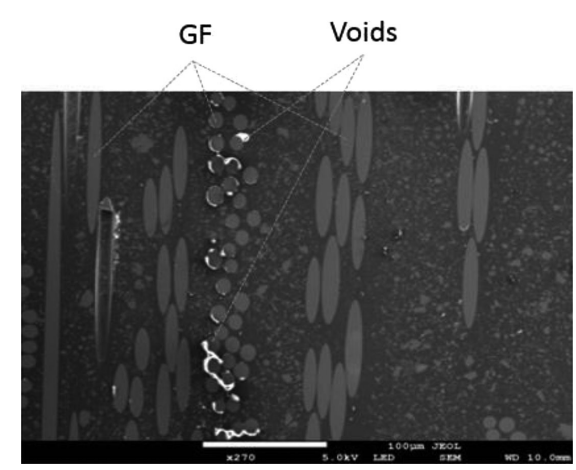

B)

Fig. 4. SEM observation cross section of $A P C(A)$ and $G F C(B)$

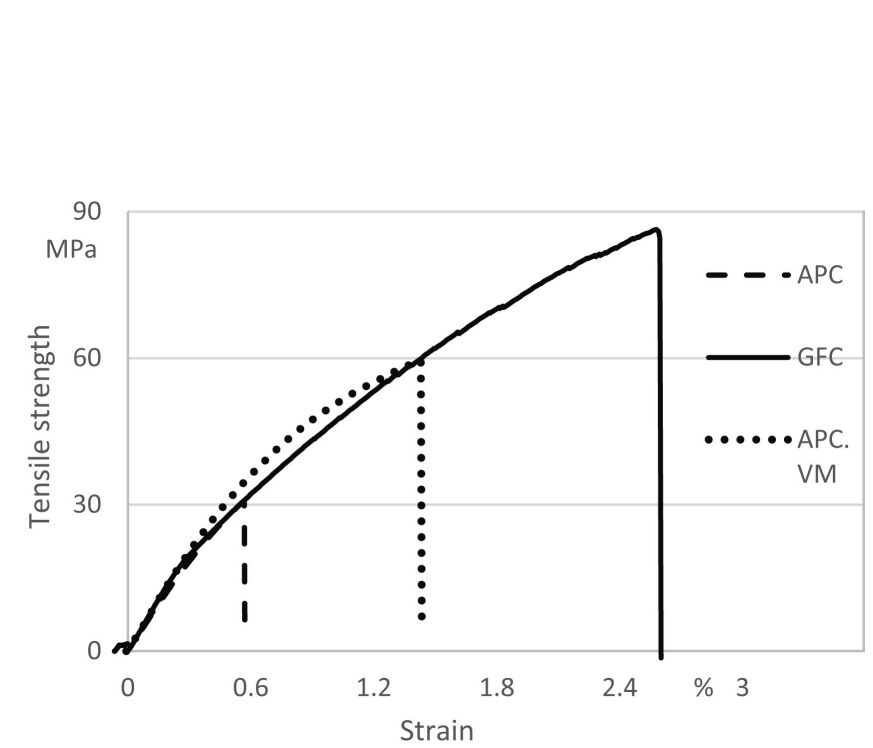

A)

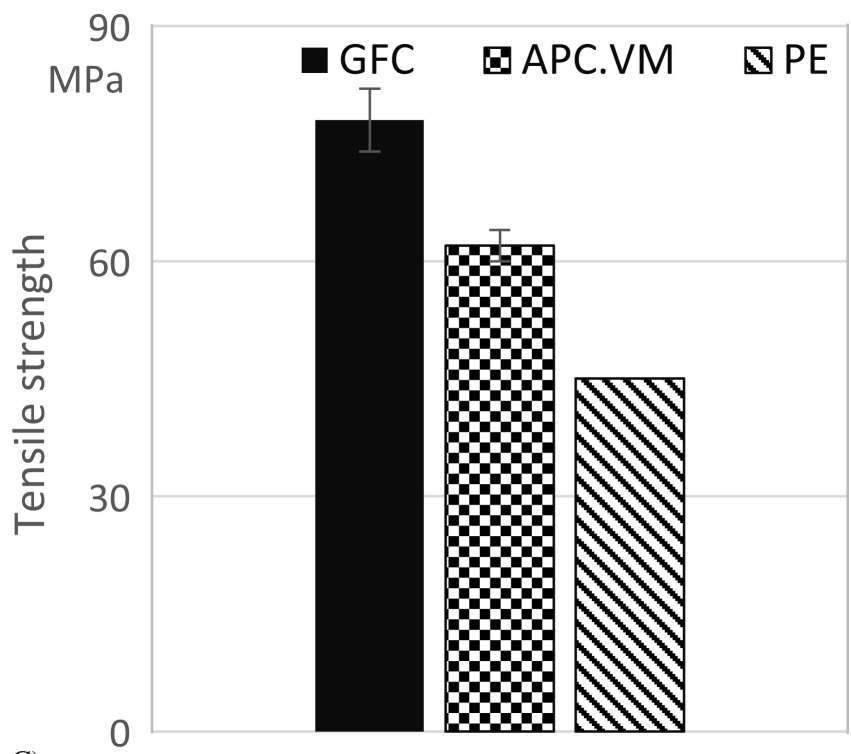

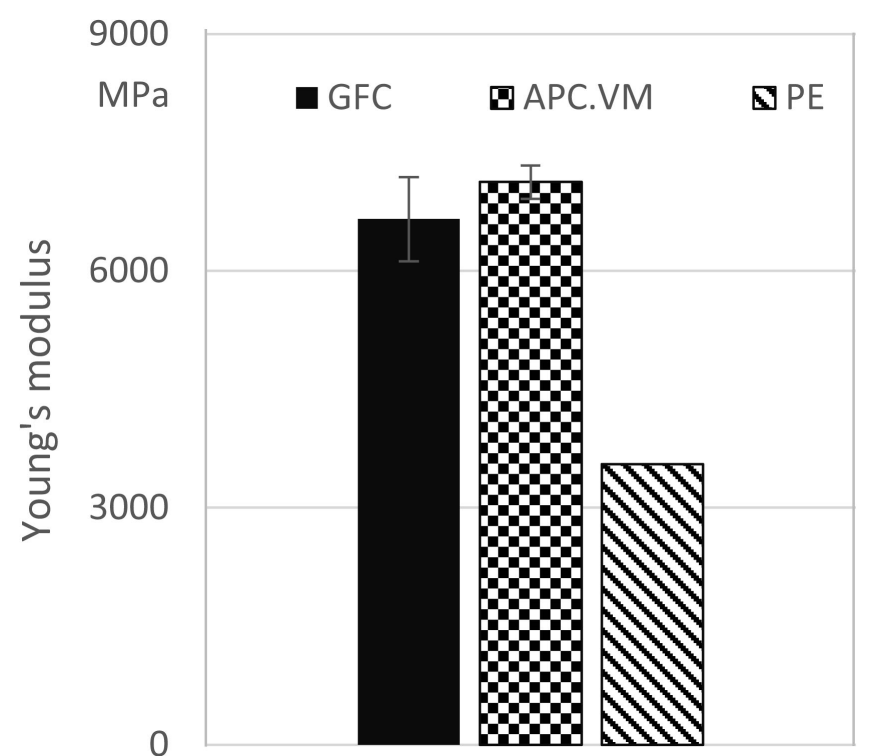

B)

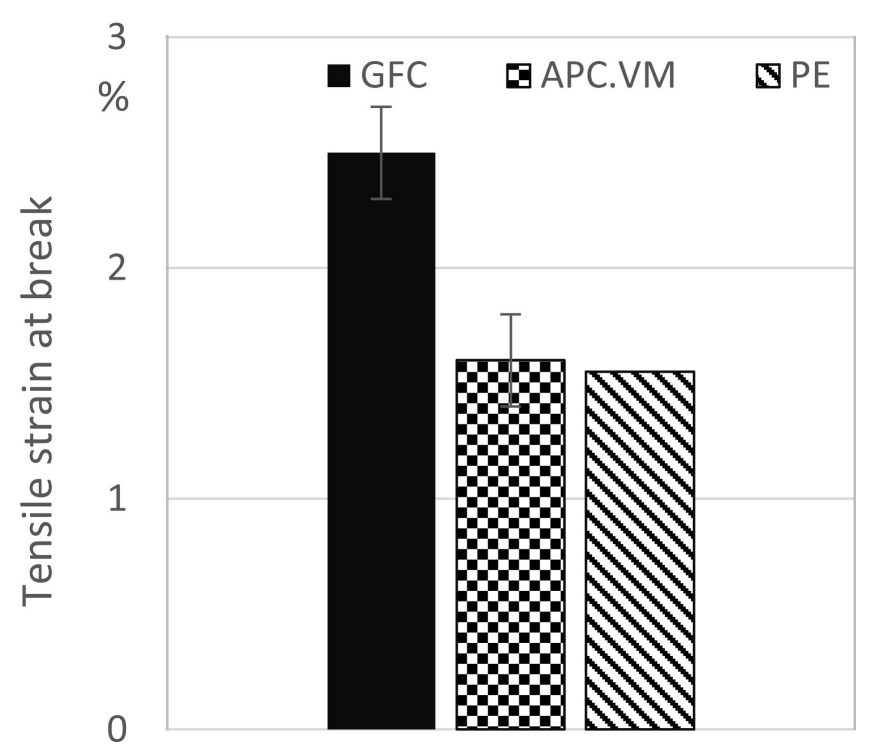

D)

Fig. 5. Tensile properties of GFC, APC (by vacuum molding process) and PE: A) curve of tensile test (stress-strain), B) tensile stiffness of GFC and APC.VM comparing to PE, C) tensile strength of GFC and APC.VM, D) tensile strain at break of GFC and APC.VM 


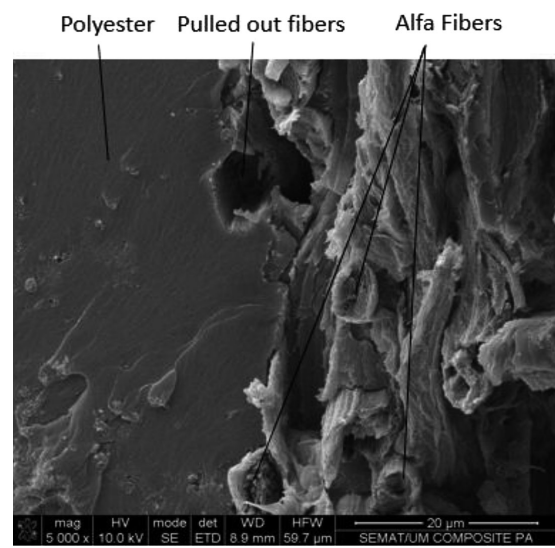

A)
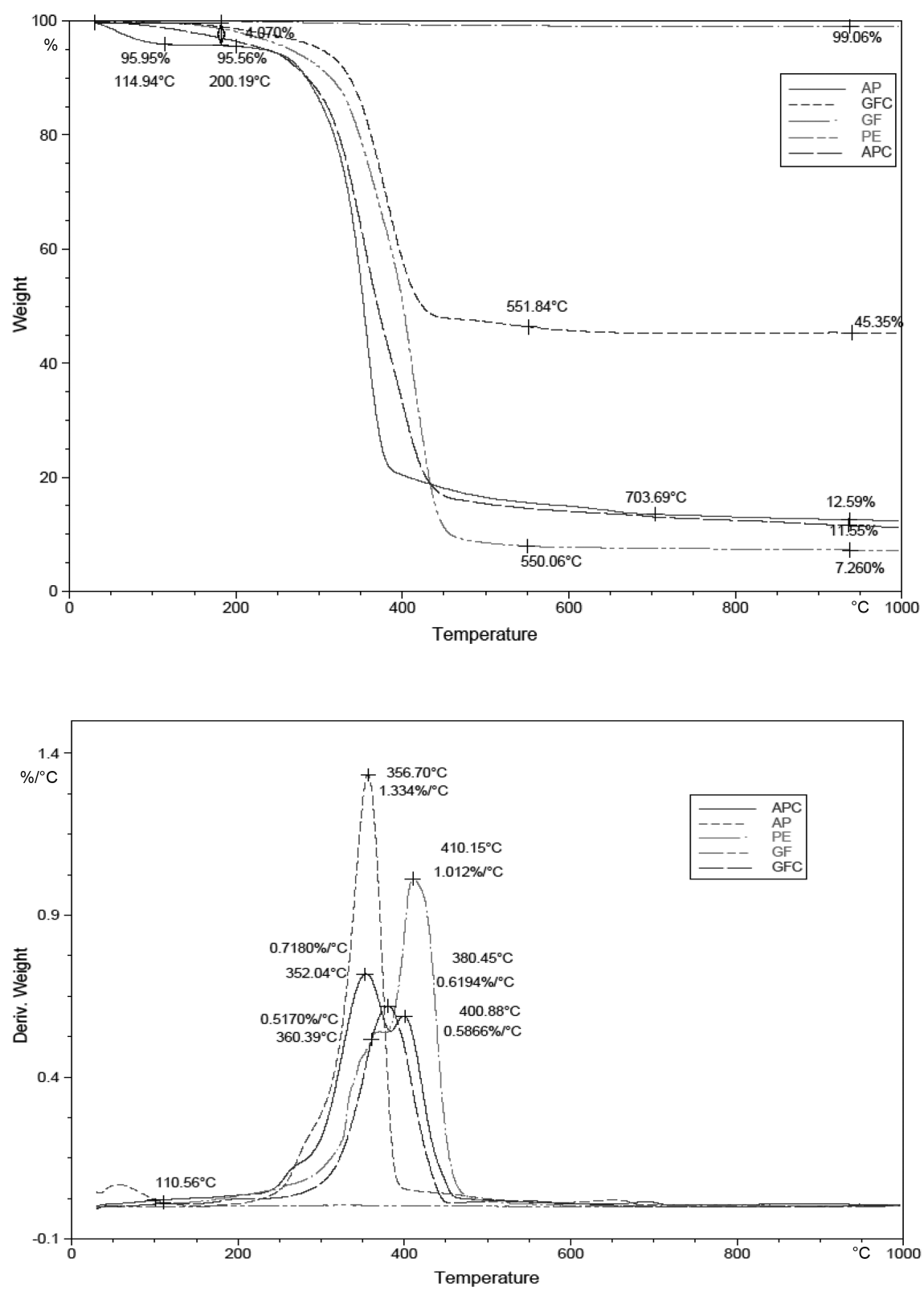

Fig. 6. SEM of composites cross the thickness: A) $A P C, B) G F C$

Fig. 7. TGA curves obtained for the materials $(P E, A P, A P C, G F, G F C)$

Fig. 8. Derivative of TGA curves (DTG) presented in Fig. 6

Intern. Polymer Processing XXXIV (2019) 1 
tent. The DTG curves represented in Fig. 8 show that the thermal degradation of the AP occurs through one major degradation step with maximum rate at $356.7^{\circ} \mathrm{C}$, while $\mathrm{PE}$ undergoes at least two major degradation processes, the first presenting a lower maximum degradation rate at $360^{\circ} \mathrm{C}$ and the second with a higher rate occurring at $410^{\circ} \mathrm{C}$. APC presents the characteristic degradation step of AP and another, at higher temperature, associated with the PE degradation, while GFC shows one major process occurring over a wide temperature range.

\subsubsection{Differential Scanning Calorimetry}

The DSC analysis was carried out to characterize the thermal transitions of the PE polymer and AP fibers, and to observe any changes that may occur due to composite formation and PE/fiber interaction. All the materials were analyzed. The curves corresponding to the first heating are presented in Fig. 9, and those corresponding to the second heating in Fig. 10.

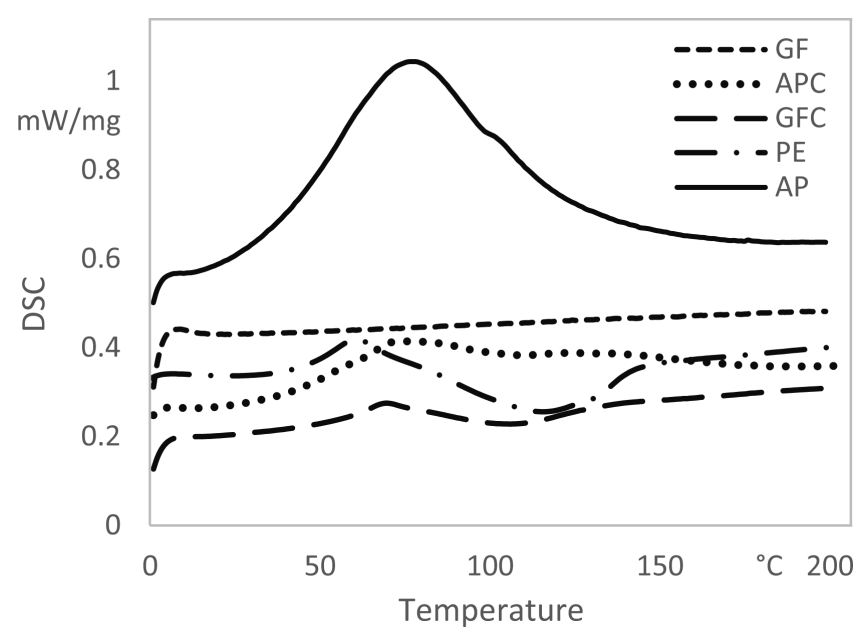

Fig. 9. DSC curves of the first heating for the samples (AP, PE, GF, $A P C, G F C$ )

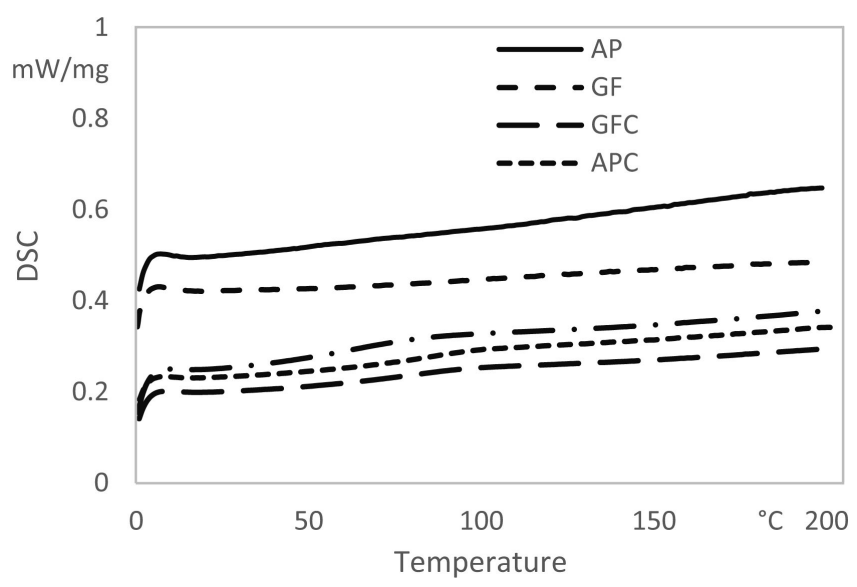

Fig. 10. DSC curves of the second heating for the samples (AP, PE, $G F, A P C, G F C)$
The first heating shows an endothermic peak for AP, which is typical of hydrophilic materials and lignin containing materials. This endothermic peak results from the vaporization of low molecular weight molecules contained in lignin and hemicellulose, and from the moisture present in the AP. This water is strongly bonded to the hydrophilic groups in cellulose, and thus requires heating above $100^{\circ} \mathrm{C}$ in order to completely vaporize. The first heating of the $\mathrm{PE}$ polymer presents a glass transition temperature $(\mathrm{Tg})$ near $60^{\circ} \mathrm{C}$, that increases by nearly $10^{\circ} \mathrm{C}$ for the composites, either with glass or AP fibers. The increase in $\mathrm{Tg}$ may be due to the decrease in polymer chain mobility in the presence of the large fraction of fiber surface.

The endothermic peaks observed for AP disappear after the first heating step, and only a low energy endothermic process is observed for PE, APC and GFC (Fig. 10).

\subsection{Discussion of the Composites Tensile Properties}

The composites produced by vacuum processing demonstrated excellent mechanical properties and thermal stability up to $200^{\circ} \mathrm{C}$. A high value for the Young's modulus was observed for the APC, even slightly higher than that obtained for GFC. Considering the higher modulus of GF compared to AP (approximately $73 \mathrm{GPa}$ and $19,3 \mathrm{GPa}$, respectively) the similar composite moduli measured for both types of PE composites is indicative that a larger amount of AP could be incorporated in the APC composite. Indeed the AP mat used for composite production was characterized by an areal weight of $524 \mathrm{~g} / \mathrm{m}^{2}$, while the GF mat presented $350 \mathrm{~g} / \mathrm{m}^{2}$. Accounting for a density for cellulose fibers and glass fibers as approximately 1.4 and 2.6, respectively, then the volume of AP is expected to be circa 2.6 times the volume of GF, within the same composite volume. The volume fraction of GF and AP within the composite may be estimated from the composites moduli measured experimentally, and the individual fibers and polyester moduli. The estimate was carried out using the Halpin-Tsai equations (Tsai, $1969 \square$ please add to the reference section as well $\square$ ) adapted for short fiber composites considering randomly oriented fibers. The composite modulus was calculated from Eq. 1,

$\mathrm{E}_{\mathrm{c}}=\mathrm{E}_{\mathrm{P}}\left\{\frac{3}{8} \frac{1+2\left(\mathrm{l}_{\mathrm{F}} / \mathrm{d}_{\mathrm{F}}\right) \eta_{\mathrm{L}} \varphi_{\mathrm{F}}}{1-\eta_{\mathrm{L}} \varphi_{\mathrm{F}}}+\frac{5}{8} \frac{1+2 \eta_{\mathrm{T}} \varphi_{\mathrm{F}}}{1-\eta_{\mathrm{T}} \varphi_{\mathrm{F}}}\right\}$,

where $\mathrm{E}_{\mathrm{c}}$ is the composite modulus, $\mathrm{E}_{\mathrm{P}}$ is the polymer modulus, $\phi_{\mathrm{F}}$ is the volume fraction of the fiber, $\left(\mathrm{l}_{\mathrm{F}} / \mathrm{d}_{\mathrm{F}}\right)$ is the fiber aspect ratio, and $\eta_{\mathrm{L}}, \eta_{\mathrm{T}}$ are given by Eq. 2 and 3, respectively:

$\eta_{\mathrm{L}}=\frac{\left(\mathrm{E}_{\mathrm{F}} / \mathrm{E}_{\mathrm{P}}\right)-1}{\left(\mathrm{E}_{\mathrm{F}} / \mathrm{E}_{\mathrm{P}}\right)+2\left(\mathrm{l}_{\mathrm{F}} / \mathrm{d}_{\mathrm{F}}\right)}$,

$\eta_{\mathrm{T}}=\frac{\left(\mathrm{E}_{\mathrm{F}} / \mathrm{E}_{\mathrm{P}}\right)-1}{\left(\mathrm{E}_{\mathrm{F}} / \mathrm{E}_{\mathrm{P}}\right)+2}$

where $\mathrm{E}_{\mathrm{F}}$ is the fiber modulus. Considering the following approximate moduli values: $3,55 \mathrm{GPa}$ for polyester, $73 \mathrm{GPa}$ for GF and 19.3 GPa for the AP (Paiva et al., 2007), and that the fibres cross section is approximately circular and the fibres aspect ratio is at least 50 , then the estimated composite moduli variation with fiber volume composition is represented in Fig. 11. 


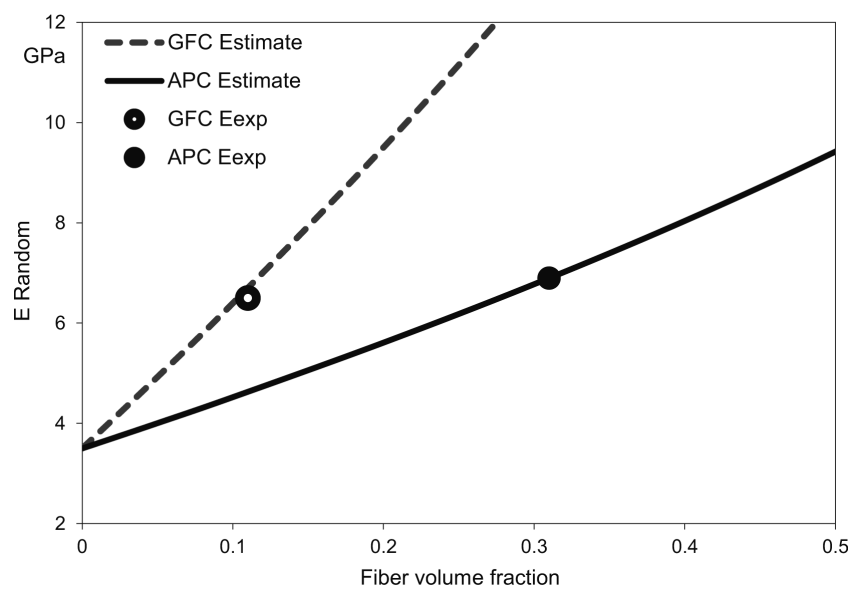

Fig. 11. Composite moduli estimated using the Halpin-Tsai equations assuming a short fiber random distribution

Considering the experimental results obtained for the composites moduli, then the fiber volume content can be estimated as approximately $11 \%$ for GFC and $31 \%$ for APC, from the modulus estimate curves represented in Fig. 11. This result matches the expected fiber volume relation based on the fibre mats areal weight.

\section{Conclusions}

The objective of this work was to prepare a polyester composite reinforced with Alfa pulp and compare its morphology, mechanical and thermal properties with those of the most commonly used polyester/glass fibers composites. The composites were prepared by two different processing routes.

The result demonstrated a significant improvement in tensile properties of APC processed by vacuum molding. SEM observation showed improved interfacial bonding for the composites prepared by this process.

The tensile proprieties of the APC prepared by vacuum molding reached a similar order of magnitude as those of GFC. Thermal analysis showed that APC composite presented similar thermal stability as the polyester resin. In conclusion it was observed that APC may replace GFC for applications that require the level of mechanical and thermal performance typical of GFC.

\section{References}

Albano, C., Gonzalez, J., Ichazo, M. and Kaiser, D., "Thermal Stability of Blends of Polyolefins and Sisal Fiber", Polym. Degrad. Stab., 66, 179-90 (1999), DOI:10.1016/S0141-3910(99)00064-6

Ammar, I., Ben Cheikh, R., Campos, A. R. and Cunha, A. M., "Injection Molded Composites of Short Alfa Fibres and Biodegradable Blends", Polym. Compos., 27, 341-348 (2006), DOI: $10.1002 / \mathrm{pc} .20196$

Baley, C., Busnel, F., Grohens, Y. and Sire, O., "Influence of Chemical Treatments on Surface Properties and Adhesion of Flax FibrePolyester Resin", Composites Part A, 37, 1626-1637 (2006), DOI:10.1016/j.compositesa.2005.10.014
Belgacem, M. N., Bataille, P. and Sapieha, S., "Effect of Corona Modifi Cation on the Mechanical Properties of Polypropylene/Cellulose Composites", J. Appl. Polym. Sci., 53, 379-385 (1994), DOI:10.1002/app.1994.070530401

Ben Brahim, S., Ben Cheikh, R. and Baklouti, M., "The Alfa Fibers in Composite Materials", ICCM-13 Conference, Beijing, PRC (2001)

Ben Brahim, S., Ben Cheikh, R., "Influence of Fibre Orientation and Volume Fraction on the Tensile Properties of Unidirectional AlfaPolyester Composite", Compos. Sci. Technol., 67, 140-147 (2007), DOI:10.1016/j.compscitech.2005.10.006

Campos, A. R., Cunha, A. M. and Ben Cheikh, R., "Injection Molding of a Starch Based Polymer Reinforced with Natural Fibres", $\square$ SPE ANTEC Tech. Papers, $\square-\square \square$ (2003) $\square$ SPE ANTEC Conference, Nashville, USA (2003)

Chuai, C., Almdal, K., Poulsen, L. and Plackett, D., "Conifer Fibers as Reinforcing Materials for Polypropylene-Based Composites", J. Appl. Polym. Sci., 80, 2833-2841 (2001), DOI:10.1002/app.1400

Ellouze, A., Jesson, D. and Ben Cheikh, R., "Do Production Process Influence the Mechanical Propreties of Bleached Alfa Pulpboard?, Cellulose, 24, 2313-2329 (2017), DOI:10.1007/S10570-017-1261-6

Farag, M. M., "Quantitative Methods of Materials Substituion: Application to Automotive Component", Mater. Des., 29, 374-380 (2008), DOI:10.1016/j.matdes.2007.01.028

Felix, J. M., Carlsson, C. M. G. and Gatenholm, P., "Adhesion Characteristics of Oxygen Plasma-Treated Rayon Fibers", J. Adhes. Sci. Technol., 8, 163-180 (1994), DOI:10.1163/156856194X00131

Garcia-Fayos, P., Gasque, M., "Seed vs. Microsite Limitation for Seedling Emergence in the Perennial Grass Stipatenacissima L. (Poaceae)", Acta. Oecol., 30, 276-282 (2006),

DOI:10.1016/j.actao.2006.05.003

Gassan, J., Gutowski, V. S., "Effects of Corona Discharge and UV Treatment on the Properties of Jute- Fiber Epoxy Composites", Compos. Sci. Technol., 60, 2857-2863 (2000), DOI:10.1016/S0266-3538(00)00168-8

Gloria, G. O., Teles, M. C. A., Lopes, F. P. D., Vieira, C. M. F., Margem, F. M., Gomes, M. A. and Monterio, S. N., "Tensile Strength of Polyester Composites Reinforced with PALF", J. Mater. Res. Technol., 6, 401 -405(2017), DOI:10.1016/j.jmrt.2017.08.006

Halpin, J. C., "Stiffness and Expansion Estimates for Oriented Short Fiber Composites", J. Compos. Mater., 3, $732-734$ (1969), DOI: $10.1177 / 002199836900300419$

Holbery, J., Houston, D., "Natural-Fiber-Reinforced Polymer Composites in Automative Applications", JOM, 58, 80-86 (2006), DOI:10.1007/S11837-006-0234-2

Jacob John, M., Thomas, S., "Biofibers and Biocomposites", Carbohydr. Polym., 71, 343-364 (2008), DOI: $10.1016 /$ j.carbpol.2007.05.040

Joffe, R., Andersons, J. and Wallstrom, L., "Strength and Adhesion Characteristics of Elementary Flax Fibres with Different Surface Treatments", Composites Part A, 34, 603-612 (2003), DOI:10.1016/S1359-835X(03)00099-X

Kaddami, H., Dufresne, A., Khelifi, B., Bendahou, A., Taourirte, M., Raihane, M., Issartel, N., Sautereau, H., Gérard, J. F. and Sami, N., "Short Palm Tree Fibers - Thermoset Matrices Composites", Composites Part A, 37, 1413-1422 (2006),

DOI:10.1016/j.compositesa.2005.06.020

Karmaker, A. C., Hoffmann, A. and Hinrichsen, G., "Influence of Water Uptake on the Mechanical Properties of Jute Fibre Reinforced Polypropylene", J. Appl. Polym. Sci., 54, 1803-1807 (1994), DOI:10.1002/app.1994.070541203

Khiari, R., Mhenni, M. F., Belgacem, M. N and Mauret, E. E., "Chemical Composition and Pulping of Date Palm Rachis and Posidoniaoceanica - A Comparison with other Wood and Non-Wood Fiber Sources", Bioresour. Technol., 101, 775-780 (2010), PMid:19766481; DOI:10.1016/j.biortech.2009.08.079

Kostic, M., Pejic, B. and Skundric, P., "Quality of Chemically Modified Hemp Fibers", Bioresour. Technol., 99, 94-99 (2008), PMid:17240139; DOI:10.1016/j.biortech.2006.11.050

Liu, F. P., Wolcott, M. P., Gardner, D. J. and Rials, T. G., "Characterisation of the Interface between Cellulosic Fibres and a Thermoplastic Matrix", Compos. Interface., 2, 419-432 (1994), DOI:10.1163/156855494X00319 
Mohanty, A. K., Misra, M. and Hinrichsen, G., "Biofibres, Biodegradable Polymers and Biocomposites: An Overview", Macromol. Mater. Eng., 276/277, 1-24 (2000), DOI:10.1002/(SICI)14392054(20000301)276:1<1::AID-MAME1>3.0.CO;2-W

Ouajai, S.,Shanks, R. A., "Composition, Structure and Thermal Degradation of Hemp Cellulose after Chemical Treatments", Polym. Degrad. Stab., 89, 327-35(2005),

DOI:10.1016/j.polymdegradstab.2005.01.016

Paiva, M. C., Ammar, I., Campos, A. R., Ben Cheikh, R. and Cunba, A. M., "Alfa Fibers: Mechanical, Morphological and Interfacial Characterization", Compos. Sci. Technol., 67, 1132-1138 (2007), DOI:10.1016/j.compscitech.2006.05.019

Rana, A. K., Basak, R. K., Mitra, B. C., Lawther, M. and Banerjee, A. N., "Studies of Acetylation of Jute Using Simplified Procedure and Its Characterization", J. Appl. Polym. Sci., 64, 1517-1523 (1997), DOI:10.1002/(SICI)1097-4628(19970523)64: 8<1517::AID-APP9>3.0.CO;2-K

Satyanarayana, K. G., Sukumaran, K., Mukherjee, P. S. and Pillai, S. G. K., "Materials Science of Some Lignocellulosic Fibers", Metallography, 19, 389-400 (1986), DOI:10.1016/0026-0800(86)90073-X

Satyanarayana, K. G., Sukumaran, K., Mukherjee, P. S., Pavithran, C. and Pillai, S. G. K., "Natural Fiber-Polymer Composites", Cement. Concrete. Compos., 12, 117-136 (1990), DOI:10.1016/0958-9465(90)90049-4

Seth, R. S., "The Importance of Fibre Straightness for Pulp Strength", Pulp. Pap. Can., 107, 1 -9 (2006), DOI:200902299298131410

Thomsen, A. B., Thygesen, A., Bohn, V., Nielsen, K. V., Pallensen, B. and Jørgensen, M. S., "Effects of Chemical Physical Pre-Treatment Processes on Hemp Fibres for Reinforcement of Composites and for Textiles", Ind. Crop. Prod., 24, $113-118$ (2006), DOI:10.1016/j.indcrop.2005.10.003

Troedec, M. L., Sedan, D., Peyratout, C., Bonnet, J. P., Smith, A., Guinebretiere, R., Gloaguen, V. and Krausz, P., "Influence of Various Chemical Treatments on the Composition and Structure of Hemp Fibres", Composites Part A, 39, 514-522 (2008), DOI:10.1016/j.compositesa.2007.12.001

Van De Weyenberg, I., Truong, T. C., Vangrimde, B. and Verpoest, I., "Improving the Properties of UD Flax Fibre Reinforced Composites by Applying an Alkaline Fibre Treatment", Composites Part A, 37, 1368-1376, (2006),

DOI:10.1016/j.compositesa.2005.08.016
Wambua, P., Ivens, J. and Verpoest, I., "Natural Fibers: Can They Replace Glass in Fibre Reinforced Plastics?", Compos. Sci. Technol., 63, 1259-64 (2003), DOI:10.1016/j.compositesa.2005.08.016

Zafeiropoulos, N. E., Dijon, G. G. and Baillie, C. A., "A Study of the Effect of Surface Treatments on the Tensile Strength of Flax Fibres", Composites Part A, 38, 621-628 (2007),

DOI:10.1016/j.compositesa.2006.02.004

\section{Acknowledgements}

The authors would like to thank CTC (Centre technique de la Chimie) for their valuable help during mechanical testing. The company Solutions Composites, especially Mr.Adel Hammami is gratefully acknowledged for financial and material support. The authors also wish to thank the members of the Department of Polymer Engineering University of Minho, Guimarães, Portugal for their valuable cooperation. This research work is carried out as part of a mobidoc $\mathrm{PhD}$, a program financed by the European Union within Pasri Projet. M.C Paiva acknowledges the Portuguese Foundation for Science and Technology (FCT) and the European program FEDER/COMPETE for the financial support through project PEst-C/CTM/ LA0025/2013 (LA 25-2015-2017).

Date received: January 09, 2018

Date accepted: May 26, 2018

Bibliography

DOI 10.3139/217.3652

Intern. Polymer Processing

XXXIV (2019) 1; page 1-10

(c) Carl Hanser Verlag $\mathrm{GmbH} \& \mathrm{Co} . \mathrm{KG}$

ISSN 0930-777X 